\title{
Evaluation of Fixed Denture Prosthetic Restorations with Pier Abutment
}

\author{
Umut Ozdal (Corresponding author) \\ Trakya University, Faculty of Dentistry, \\ Department of Prosthodontics, Edirne, Turkey \\ Ozge Ozdal Zincir, \\ Maxillofacial Surgeon, Private Practise, Istanbul, Turkey \\ Aysegul Kurt \\ Trakya University, Faculty of Dentistry, \\ Department of Prosthodontics, Edirne, Turkey \\ E-mail: umutozdal@hotmail.com
}

\begin{abstract}
The aim of this study is to evaluate the prosthetic, periodontal, radiographic and clinical findings of the fixed on-tooth restorations with middle base and observe the changes of these values over time. 24 patients were included in our study, and these patients were measured twice, one year between measurements. Statistical analyzes were performed in IBM SPSS Statistical Software program (version 21; IBM, Armonk, NY). In these analyzes, parameters such as age, gender, distance between the abutments, bridge angle, occlusion type, opposite arc type, vitality of the teeth, amount of attached gingiva, root length, restoration length, gingival pocket amount of the abutment teeth, gingival index, gingival bleeding index, plaque index, their relationship with clinical attachment loss changes, ceramic fracture and complications were evaluated. According to the data of our study, findings that are compatible with the literature and provide new information to the literature in terms of clinical loss of attachment, occurrence of periodontal diseases or complications related to restoration in patients who underwent rigid fixed prosthetic restoration, and the changes recorded in the controls performed. For this reason, we believe that rigid fixed prosthetic restorations will be more advantageous in laboratory practice, since non-rigid restorations require more complicated laboratory work, and we believe that clinical and radiological complications do not have a definite relationship with the type of restoration.
\end{abstract}

Keywords: Pier abutment, fixed prosthesis, periodontal tissue, prosthetic complication, tooth supported prosthesis.

DOI: $10.7176 / \mathrm{JSTR} / 6-10-11$

\section{Introduction}

Fixed dental prostheses (FDPs) treatment is one of the treatment methods performed by dentists for many years in order to regain the loss of function, phonification and aesthetics resulting from the teeth lost due to various reasons and to prevent the psychological disorder that occurs as a secondary factor in patients.

FDPs protocol can vary in a wide range, such as single tooth restoration, partial tooth deficiency treatment and rehabilitation of the entire dental arch in complete edentulous cases (von Stein-Lausnitz et al, 2019). Although this treatment method varies according to the indication, it has two different alternatives, tooth supported and implant supported. The selection of materials to be used according to the treatment alternatives that vary depending on the indication is also one of the factors that increase the variety in this context. Due to technological developments in the field of dentistry, as in many sectors in recent years, much progress has been achieved both within the scope of digital system and prosthetic materials. In the field of fixed prosthetic rehabilitation, it can be said that the choice to be made is simpler as the number of materials is limited compared to the type of restoration to be carried out in the 1970s. In this period, while using the gold alloy casting method in fixed prostheses to be

126 | P a g e

www.iiste.org 
applied to the posterior teeth, polymethyl methacrylate (PMMA) or ceramic materials with metal substructure were used in the restoration in the anterior region, which is a relatively more aesthetic area (Roberts, 2013 ).

While FDPs have a wide range of uses, various complications can be encountered with long-term use. These complications can be in the mechanical or aesthetic framework of restoration such as fracture of the prosthesis, ceramic cracking, change in ceramic color, as well as changes in periodontal tissues and bone levels (Walton, 2015).

The aim of our study is to evaluate the complications or improvements that may occur in the follow-up of metal-ceramic tooth-supported FDPs that have 3 abutments applied in 24 patients, mesial and distal body of the pier abutment and at least 5 units.

\section{Method}

The study was conducted with 24 patients (13 females, 11 males) between the ages of 18-70 who applied to the Trakya University Oral and Dental Health Application and Research Center for dental treatments between 2015 and 2018, and were treated with a fixed prosthetic restoration with a middle abutment. Before starting the study, approval was obtained from Trakya University Faculty of Medicine Scientific Research Ethics Committee with TÜTF-BAEK 2019/4 Protocol Code and 03/35 Decision Number on 11.02.2019.

The 12-month clinical and radiographic evaluations of the patients between the first control date and the second control date were examined. All these evaluations were classified into 5 main groups: dental, gingival and periodontium, radiographic, restorative and complication type.

The number of the abutment tooth, whether the tooth is vital or devital, the distance between the 1st and 2nd abutment teeth, the distance between the 2nd and the 3rd abutment are the parameters related to the evaluated tooth.

Probing pocket depth, gingival index, bleeding on probing, plaque index and the amount of attached gingiva are parameters related to the gingiva and periodontium.

Tooth root shape, post presence, tooth root length, presence and amount of resorption in the tooth root are the parameters evaluated radiographically.

Restoration length (distance between gingiva and incisal border), presence of cantilever, bridge angle, occlusion type, presence of natural tooth or restoration in the opposite arch, presence of ceramic fracture, presence of bridge fracture, and if there is a fracture, the location of the fracture are the parameters evaluated in relation to the restoration. In our study, the clinical crown length of the restoration was measured with a manual periodontal probe (Hu-Friedy; Chicago, IL, USA). In order to determine the bridge angle, the wax bite was taken from the patient and the angle between the 2 lines connecting the occlusal contact points of the 3 abutment crowns in the restoration was measured with a protractor.

The types of complications evaluated were divided into three groups as biological, mechanical and aesthetic complications. Exposure of the cole region due to gingival recession, subsequent mobility in the tooth, damage to the neighboring tooth involving the crown or periodontium, destruction of the opposing teeth, mesial and distal alveolar bone resorption in the abutment teeth were evaluated as biological complications. Cracks or fractures in the bridge infrastructure or superstructure material, abrasion or loss of material in the bridge material, frequent desiccation of the bridge were considered as mechanical complications. Aesthetic complications were considered as material loss, color change in the ceramic material, negative effects on the aesthetics due to gingival recession or growth, which would adversely affect the appearance of the bridge.

These examinations are as follows: vitality evaluation of teeth (vital, devital), periodontal pocket amount (mesiobuccal $[\mathrm{MB}]$, buccal $[\mathrm{B}]$, distobuccal [DB], mesiopalatinal [MP], palatinal [P], distopalatinal [DP] with 0-1-2-3 mm measurements), gingival index (mesial, distal, buccal, degree of inflammation with palatinal measurements 0-1-2-3-4 grading), bleeding index (as " + " or " - " with mesial, buccal, distal, palatinal measurements), plaque index (mesial, buccal, distal, palatinal measurements with 0-1-2-3 quantity grading), dura width, root shape (single - straight), presence of post (in " + " or " - "), amount of attached gums (millimeters ), root length (in centimeters), crown length (in millimeters), presence of cantilever (in " + " or " - "), type of cross arch, bridge material, presence and type of complication (biological - mechanical - as a type of aesthetic complication), the distance between the 1 st and 2 nd abutment teeth, the distance between the 2nd and 3rd abutment teeth, the bridge angle.

127 | P a g e

www.iiste.org 
Measurements were made with a Williams (Hu Friedy, Chiago, USA) type periodontal probe in 6 regions (MB, DB, B, MP, P and DP) in all teeth.

Between the two controls, changes in the amount of gingival pockets, gingival index, bleeding, plaque amount and bone amount in the cole, ceramic fracture and complications (biological, mechanical, aesthetic) were taken as dependent variables, and the patient's age, gender, type of opposite arch, the distance between the 1 st and 2 nd abutments, the distance between the 2 nd and 3rd abutments, the angle of the bridge prosthesis, the type of occlusion, the vitality of the tooth, the amount of attached gingiva, root length and restoration length were taken as independent variables and their statistical relationships or comparisons were made.

\subsection{Statistical analysis}

Descriptive statistics were used to describe continuous variables (mean (Avg.), Standard deviation (SD), minimum (Min.), Median (Med.), Maximum (Max.)). Frequency (N) and percentage (\%) values were used to define categorical variables. Comparison of continuous variables belonging to more than two groups that do not conform to normal distribution was made with the Kruskal Wallis test. Multiple comparison analysis for variables found to be significant was performed using the Mann-Whitney U test, and Bonferroni correction was used. Fisher Exact test statistics were used to examine the relationship between categorical variables. Spearmen correlation test was used for the size of the relationship between two continuous variables and the correlation coefficient (r) was interpreted according to the values obtained. The statistical significance level was set at 0.05 . For statistical analysis, IBM SPSS Statistical Software (version 21; IBM, Armonk, NY) was used.

\section{Results}

3.1. Change Findings in the Amount of Gingival Pockets

3.1.1. Findings of change in the amount of gingival pockets

It was observed that there was no statistically significant relationship between the first abutment teeth and the age factor ( $p>0.05)$. The increase in the amount of pockets of the 2 nd abutment teeth has a statistically moderate relationship with age $(\mathrm{r}=0.41 ; \mathrm{p}=0.048)$. The increase in the number of pockets of the $3 \mathrm{rd}$ abutment has a statistically significant moderate relationship with age $(\mathrm{r}=0.56 ; \mathrm{p}=0.005)$ (Table-1).

Table-1. Change between age and pocket quantity

\begin{tabular}{|l|l|l|}
\hline \multirow{2}{*}{} & \multicolumn{2}{|c|}{ Change in pocket amount } \\
\cline { 2 - 3 } & 2nd abutment DB surface & 3rd abutment DB surface \\
\hline Age & $\mathrm{r}=0.41$ & $\mathrm{r}=0.56$ \\
& $\mathrm{p}=0.048$ & $\mathrm{p}=0.005$ \\
\hline
\end{tabular}

Spearman Correlation Test

\subsubsection{Relationship between gender and pocket amount}

The Mann-Whitney U test was used for the comparison between the changes in the amount of pockets of the abutment teeth and the gender factor. According to the sample, the change in the amount of pockets in all abutments is independent of gender $(p>0.05)$.

\subsubsection{Correlation between pocket amount change and distance between abutments}

There is a statistically significant and moderate relationship between the increase in the distance between the first and second abutments and the decrease in the amount of pockets only in the $\mathrm{P}$ region of the first abutment $(\mathrm{r}=-0.52 ; \mathrm{p}=0.01)$. There is a statistically significant and moderate relationship between the increase in the distance between the first and the second abutment and the decrease in the amount of pockets only in the MB region of the second abutment $(\mathrm{r}=-0.41 ; \mathrm{p}=0.05)$. There is no statistically significant correlation between the distance between the first and second abutments and the change in the pocket amount in all regions of the third abutment ( $p>0.05)$. There is a statistically significant and moderate relationship between the increase in the distance between the second and third abutments and the decrease in the amount of pockets only in the DB region of the first abutment $(r=-$

128 | P a g e

www.iiste.org 
$0.41 ; \mathrm{p}=0.02)$. There is a statistically significant and moderate relationship between the increase in the distance between the second and third abutments and the decrease in the amount of pockets only in the $\mathrm{B}$ region of the second abutment $(\mathrm{r}=-0.42 ; \mathrm{p}=0.04)$. There are statistically significant and moderate correlations between the increase of the distance between the second and third abutments with the decrease in pocket amount in the MB zone $(r=-0,41 ; p=0,04)$, in the MP zone $(r=-0,46 ; p=0,02)$, in the $\mathrm{P}$ zone $(\mathrm{r}=-0,44 ; \mathrm{p}=0,03)$ and in the DP zone $(\mathrm{r}=-0,48 ; \mathrm{p}=0,01)$ of the third abutment (Table-2).

Table-2. Correlation between pocket amount change and distance between abutments

\begin{tabular}{|l|l|l|}
\hline \multirow{2}{*}{} & \multicolumn{2}{|c|}{ Change in pocket amount } \\
\cline { 2 - 3 } & 1st abutment P surface & 2nd abutment MB surface \\
\hline Distance between 1st and 2nd & $\mathrm{r}=-0.52$ & $\mathrm{r}=-0.41$ \\
abutments & $\mathrm{p}=0.01$ & $\mathrm{p}=0.05$ \\
\hline
\end{tabular}

\begin{tabular}{|l|l|l|l|c|c|c|}
\hline & \multicolumn{5}{|c|}{ Change in pocket amount } \\
\cline { 2 - 7 } & 1st abutment & 2nd abutment & \multicolumn{3}{c|}{ 3rd abutment } \\
\cline { 3 - 7 } & DB surface & B surface & MB & MP & $\mathrm{P}$ & DP \\
\hline Distance between 2nd & $\mathrm{r}=-0.41$ & $\mathrm{r}=-0.42$ & $\mathrm{r}=-0.41$ & $\mathrm{r}=-0.46$ & $\mathrm{r}=-0.44$ & $\mathrm{r}=-0.48$ \\
and 3rd abutments & $\mathrm{p}=0.02$ & $\mathrm{p}=0.04$ & $\mathrm{p}=0.04$ & $\mathrm{p}=0.02$ & $\mathrm{p}=0.03$ & $\mathrm{p}=0.01$ \\
\hline
\end{tabular}

\subsubsection{Comparison of change in pocket amount and bridge angle}

Spearman correlation test was applied to evaluate the relationship between the changes in the amount of pockets of the abutment teeth and the bridge angle. There is no statistically significant relationship between the bridge angle and the change in pocket amount in all abutment areas ( $>0.05)$.

\subsubsection{Comparison of the change in the amount of pockets of abutment teeth with the occlusion type} Mann-Whitney U test was used to compare the changes in the amount of pockets of abutment teeth and the type of occlusion variable. According to the sample, no relationship was found between the change in the amount of pockets of all abutments and the type of occlusion ( $p>0.05)$.

\subsubsection{Comparison between changes in pocket amount and counter arc type variable}

The Kruskal Wallis test was used to compare the changes in the amount of pockets of the abutment teeth and the opposite arch type variable. According to the patient population in the study, the changes in the amount of pockets of all abutment regions are independent of the cross-arc type ( $p>0.05)$.

\subsubsection{Comparison between pocket amount change and vitality of abutments}

The change in the amount of pockets on all surfaces of the first abutment is independent of the vitality status of the teeth ( $p>0.05)$. The median of change in the amount of pockets on the DP surface of the second abutments, which are vital, is statistically significantly higher than the devital ones $(\mathrm{p}=0.03)$. The change in the amount of pockets on all surfaces of the third abutment is independent of the vitality status of the teeth $(\mathrm{p}>0.05)($ Table-3). 
Table-3. Comparison between pocket amount change and vitality of abutments

\begin{tabular}{|l|l|l|l|}
\hline \multicolumn{2}{|c|}{} & Pocket Amount Change & \multirow{2}{*}{$p$} \\
\cline { 3 - 3 } & Average Median Values & \\
\hline \multirow{2}{*}{ Vitality (DP) } & Vital $(\mathrm{n}=18)$ & 14.08 & \multirow{2}{*}{0.032} \\
\cline { 2 - 3 } & Devital $(\mathrm{n}=6)$ & 7.75 & \\
\hline \multirow{2}{*}{} & Mann-Whitney U Test & \\
\hline
\end{tabular}

3.1.8. Comparison of the relationship between the change in the amount of pockets and the amount of attached gingiva

Spearman correlation test was applied to question the relationship between the changes in the amount of pockets of the abutment teeth and the amount of attached gingiva. There is no statistically significant relationship between the amount of attached gingiva and the change in the amount of pockets in all abutment areas $(\mathrm{p}>0.05)$.

\subsubsection{Comparison of the change in pocket amount and root length}

Spearman correlation test was performed to evaluate the relationship between the changes in the amount of pockets of the abutment teeth and the root length. There is no statistically significant relationship between root length and the change in pocket amount in all abutment regions ( $\mathrm{p}>0.05)$.

\subsubsection{Comparison of change in pocket amount and length of restoration}

Spearman correlation test was performed to evaluate the relationship between the changes in the amount of pockets of the abutment teeth and the length of the restoration. It can be said that there is no statistically significant relationship between the restoration length and the change in the amount of pockets in all abutment areas $(\mathrm{p}>0.05)$.

\subsection{Change Findings in the Gingival Index (GI)}

\subsubsection{Correlation between GI and age variables}

It was observed that there was no statistically significant relationship between the GI in the first and second abutment teeth and age variables $(\mathrm{p}>0.05)$. There is a moderate statistical relationship between the third abutment teeth in the direction of the decrease in the GI and the age factor $(r=0.54 ; p=0.01)$ (Table-4).

Table-4. Correlation between GI and age variables

\begin{tabular}{|l|c|}
\hline \multirow{2}{*}{ Age } & GI \\
\cline { 2 - 3 } & Surface B of 3rd abutment \\
\hline \multirow{2}{*}{ Age } & $\mathrm{r}=0.54$ \\
$\mathrm{p}=0.01$ \\
\hline
\end{tabular}

Spearman Correlation Test

\subsubsection{Comparison of GI and gender variables}

The fact that the gingival index is higher in the direction of decrease in men and in the direction of no change in women was found to be statistically significant on the B surface $(p=0.016)$, DB surface $(p=$ $0.004)$ and $P$ surface $(p=0.04)$ of the first abutment teeth. There is no significant difference on the MB surface ( $p>0.05)$. The gingival index changes on all surfaces of the second and third abutment teeth do not show a statistically significant difference according to gender $(p>0.05)$ (Table-5). 
Table-5. Comparison of gingival index and gender variables

\begin{tabular}{|c|c|c|c|c|c|}
\hline & & \multicolumn{2}{|c|}{ Gender } & \multirow{2}{*}{$\begin{array}{c}\text { Chi Square } \\
\text { Value }\end{array}$} & \multirow[b]{2}{*}{$p$} \\
\hline & & Female & Male & & \\
\hline \multirow{3}{*}{ GI(B) } & $\begin{array}{l}\text { Inflammation } \\
\text { Increase }\end{array}$ & $\begin{array}{c}(\mathrm{n}=0) \\
\% 0\end{array}$ & $\begin{array}{l}(\mathrm{n}=1) \\
\% 9.1\end{array}$ & \multirow{3}{*}{0.27} & \multirow{3}{*}{0.002} \\
\hline & No change & $\begin{array}{l}(\mathrm{n}=11) \\
\% 84.6\end{array}$ & $\begin{array}{l}(\mathrm{n}=3) \\
\% 27.3\end{array}$ & & \\
\hline & $\begin{array}{l}\text { Inflammation } \\
\text { Reduction }\end{array}$ & $\begin{array}{c}(\mathrm{n}=2) \\
\% 15.4\end{array}$ & $\begin{array}{c}(\mathrm{n}=7) \\
\% 63.6\end{array}$ & & \\
\hline \multirow{3}{*}{ GI(DB) } & $\begin{array}{l}\text { Inflammation } \\
\text { Increase }\end{array}$ & $\begin{array}{c}(\mathrm{n}=0) \\
\% 0\end{array}$ & $\begin{array}{c}(\mathrm{n}=0) \\
\% 0\end{array}$ & \multirow{3}{*}{0.34} & \multirow{3}{*}{0.005} \\
\hline & No change & $\begin{array}{l}(\mathrm{n}=10) \\
\% 76.9\end{array}$ & $\begin{array}{l}(\mathrm{n}=2) \\
\% 18.2\end{array}$ & & \\
\hline & $\begin{array}{l}\text { Inflammation } \\
\text { Reduction }\end{array}$ & $\begin{array}{c}(n=3) \\
\% 23.1\end{array}$ & $\begin{array}{c}(\mathrm{n}=9) \\
\% 81.8\end{array}$ & & \\
\hline \multirow{3}{*}{$\mathrm{GI}(\mathrm{P})$} & $\begin{array}{l}\text { Inflammation } \\
\text { Increase }\end{array}$ & $\begin{array}{l}(\mathrm{n}=1) \\
\% 7.7\end{array}$ & $\begin{array}{l}(\mathrm{n}=1) \\
\% 9.1\end{array}$ & \multirow{3}{*}{0.21} & \multirow{3}{*}{0.007} \\
\hline & No change & $\begin{array}{l}(\mathrm{n}=10) \\
\% 76.9\end{array}$ & $\begin{array}{l}(\mathrm{n}=3) \\
\% 27.3\end{array}$ & & \\
\hline & $\begin{array}{l}\text { Inflammation } \\
\text { Reduction }\end{array}$ & $\begin{array}{l}(\mathrm{n}=2) \\
\% 15.4\end{array}$ & $\begin{array}{l}(\mathrm{n}=7) \\
\% 63.6\end{array}$ & & \\
\hline
\end{tabular}

Chi Square Goodman and Kruskal tau

\subsubsection{Relationship between GI change and distance between abutments}

Spearman correlation test was applied for the relationship between gingival index changes in all regions of the first, second and third abutment teeth and the distance between abutments. There is no statistically significant relationship between the distance between abutments and gingival index change in any of the abutment teeth $(\mathrm{p}>0.05)$.

\subsubsection{Bridge angle relation with GI change}

Spearman correlation test was used to evaluate the relationship between gingival index changes and bridge angle in all regions of the first, second and third abutment teeth. There is no statistically significant relationship between the bridge angle and the gingival index change in any of the abutment teeth $(\mathrm{p}>0.05)$.

\subsubsection{The change of GI change in the first abutment according to occlusion types}

Chi-square test was used for the comparison between gingival index changes and occlusion type variable in all regions of first, second and third abutment teeth. According to the sample, there is a significant difference between the gingival index change and occlusion type of all abutments ( $p>0.05)$.

\subsubsection{Change of GI change according to opposing arc types}

Chi-square test was used to compare the gingival index changes in all regions of the first, second and third abutment teeth and the opposite arch type variable. According to the patient population in the study, the gingival index change of all abutment regions is independent of the opposite arch type ( $\mathrm{p}$ > $0.05)$.

\subsubsection{Change of GI change according to vitality types}

Chi-square test was applied to compare the changes in gingival index in all regions of the first, second and third abutment teeth and the vitality variable of the teeth. Only the change in the gingival index on the DB surface of the third abutment was found to be statistically significant $(p=0.03)$.

\subsubsection{Comparison of gingival index change according to the amount of attached gingiva}

There is a significant relationship between the change in the gingival index on the DB surface of the first abutment and the change in the amount of attached gingiva $(p=0.01)$. Accordingly, there is no change in the amount of attached gingiva of $83.3 \%$ of the DB surfaces of the 1 st abutment teeth without any change in the gingival index. On the other hand, $41.7 \%$ of the DB surfaces of the first abutment teeth with a decrease in the gingival index do not have a change in the amount of attached

131 | P a g e

www.iiste.org 
gingiva, and there is a decrease in the amount of attached gingiva in $41.7 \%$. There is a significant relationship between the change of the gingival index on the P surface of the 1st abutment and the change in the amount of attached gingiva $(\mathrm{p}=0.01)$. Accordingly, there is no change in the amount of attached gingiva of $100 \%$ of the P surfaces of the 1st abutment teeth with an increase in the gingival index. There is no change in the amount of attached gingiva on $76.9 \%$ of the $\mathrm{P}$ surfaces of the 1 st abutment teeth whose gingival index cannot be changed, and there is a decrease in the amount of attached gingiva on $55.6 \%$ of the P surface of the 1st abutment teeth with a decrease in the gingival index change (Table-6).

Table-6. Comparison of abutment GI and amount of attached gingiva- DB and P surfaces

\begin{tabular}{|c|l|c|c|c|c|c|}
\hline \multicolumn{2}{|c|}{} & \multicolumn{2}{|c|}{ Changing the Amount of Attached Gingiva } & \multirow{2}{*}{$\begin{array}{c}\text { Chi Square } \\
\text { Value }\end{array}$} & $p$ \\
\cline { 3 - 5 } & Reduction & No change & Increase & & \\
\hline \multirow{3}{*}{ GI(DB) } & No change & $(\mathrm{n}=2)$ & $(\mathrm{n}=10)$ & $(\mathrm{n}=0)$ & & \\
& & $\% 28.6$ & $\% 66.7$ & $\% 0$ & \multirow{2}{*}{0.44} & 0.01 \\
\cline { 2 - 5 } & Inflammation & $(\mathrm{n}=5)$ & $(\mathrm{n}=5)$ & $(\mathrm{n}=2)$ & & \\
& Reduction & $\% 71.4$ & $\% 33.3$ & $\% 100$ & & \\
\hline
\end{tabular}

Chi-Square Test Kendall Tau Coefficient

\begin{tabular}{|c|c|c|c|c|c|c|}
\hline & \multicolumn{3}{|c|}{ Changing the Amount of Attached Gingiva } & \multirow{2}{*}{$\begin{array}{c}\text { Chi Square } \\
\text { Value }\end{array}$} & \multirow{2}{*}{$p$} \\
\hline & & Reduction & No change & Increase & & \\
\hline \multirow{6}{*}{$\mathrm{GI}(\mathrm{P})$} & Inflammation & $(n=0)$ & $(n=2)$ & $(\mathrm{n}=0)$ & \multirow{6}{*}{0.43} & \multirow{6}{*}{0.01} \\
\hline & Increase & $\% 0$ & $\% 13.3$ & $\% 0$ & & \\
\hline & No change & $(n=2)$ & $(\mathrm{n}=10)$ & $(\mathrm{n}=1)$ & & \\
\hline & & $\% 28.6$ & $\% 66.7$ & $\% 50$ & & \\
\hline & Inflammation & $(\mathrm{n}=5)$ & $(\mathrm{n}=3)$ & $(\mathrm{n}=1)$ & & \\
\hline & Reduction & $\% 71.4$ & $\% 20$ & $\% 50$ & & \\
\hline
\end{tabular}

Chi-Square Test Kendall Tau Coefficient

There is a significant relationship between the change of gingival index only on the MB surface of the 2nd abutment and the change in the amount of attached gingiva ( $p=0.03)$. Accordingly, $66.7 \%$ of the MB surfaces of the second abutment teeth with an increase in the gingival index do not change the amount of attached gingiva. There is no change in the amount of attached gingiva of $100 \%$ of the MB surfaces of the second abutment teeth with no change in the gingival index. There is no change in the amount of attached gingiva in $43.8 \%$ of the MB surfaces of the second abutment teeth with a decrease in the gingival index, and a decrease in the amount of attached gingiva in 50\% (Table-7).

Table-7. Comparison of the 2nd abutment GI and the amount of attached gingiva- MB surface

\begin{tabular}{|c|c|c|c|c|c|c|}
\hline & \multicolumn{3}{|c|}{ Changing the Amount of Attached Gingiva } & \multirow{2}{*}{$\begin{array}{c}\text { Chi Square } \\
\text { Value }\end{array}$} & \multirow[b]{2}{*}{$p$} \\
\hline & & Reduction & No change & Increase & & \\
\hline \multirow{3}{*}{ GI(MB) } & $\begin{array}{l}\text { Inflammation } \\
\text { Increase }\end{array}$ & $\begin{array}{c}(\mathrm{n}=1) \\
\% 11.1\end{array}$ & $\begin{array}{c}(\mathrm{n}=2) \\
\% 14.3\end{array}$ & $\begin{array}{c}(\mathrm{n}=0) \\
\% 0\end{array}$ & \multirow{3}{*}{0.36} & \multirow{3}{*}{0.03} \\
\hline & No change & $\begin{array}{c}(\mathrm{n}=0) \\
\% 0\end{array}$ & $\begin{array}{l}(\mathrm{n}=5) \\
\% 35.7\end{array}$ & $\begin{array}{c}(\mathrm{n}=0) \\
\% 0\end{array}$ & & \\
\hline & Inflammation & $\begin{array}{c}(\mathrm{n}=8) \\
\% 88.9\end{array}$ & $\begin{array}{l}(\mathrm{n}=7) \\
\% 50\end{array}$ & $(\mathrm{n}=1)$ & & \\
\hline
\end{tabular}

Chi-Square Test Kendall Tau Coefficient 
There is no significant relationship between the change of gingival index on all surfaces of the $3 \mathrm{rd}$ abutment teeth and the amount of attached gingiva $(p>0.05)$.

\subsubsection{Comparison of GI change and root length}

Spearman correlation test was applied to evaluate the relationship between gingival index changes and root length in all regions of the first, second and third abutment teeth. There is no statistically significant relationship between the gingival index change on all surfaces of all three abutments and root length $(\mathrm{p}>0.05)$.

\subsubsection{Comparison of GI change and restoration length}

Spearman correlation test was conducted to evaluate the relationship between gingival index changes and restoration length in all regions of the first, second and third abutment teeth. There is no statistically significant relationship between restoration length and gingival index change in all abutment regions ( $p>0.05)$.

\subsection{Change Findings in Gingival Bleeding}

\subsubsection{Comparison of bleeding change by age variable}

The Kruskal Wallis test was used for the relationship between gingival bleeding changes of the first, second and third abutment teeth and the age variable. It is statistically independent from the age variable of gingival bleeding changes on all surfaces of all abutment teeth $(p>0.05)$.

\subsubsection{Comparison of bleeding change and gender groups}

Chi-square test was used for the relationship between gingival bleeding changes of first, second and third abutment teeth and gender variable. According to the patient population in the study, the bleeding change in all abutments is not dependent on the gender variable ( $p>0.05)$.

\subsubsection{Comparison of bleeding change by distance between abutments}

The Kruskal Wallis test was applied for the relationship between gingival bleeding changes in all areas of the first, second and third abutments and the distance between abutments. There is no statistically significant relationship between the distance between abutments and the change in bleeding in any of the abutments ( $p>0.05)$.

\subsubsection{Comparison of bleeding change with respect to bridge angle}

The Kruskal Wallis test was used to compare gingival bleeding changes in all regions of the first, second and third abutment teeth and the bridge angle variable. According to the sample, it can be said that there is no significant difference between gingival bleeding change in all abutments and the angle of the bridge ( $p>0.05)$.

\subsubsection{Comparison of bleeding change and occlusion types}

Chi-square test was used to compare gingival bleeding changes in all regions of the first, second and third abutment teeth and the type of occlusion variable. According to the sample, there is no significant difference between the gingival bleeding change in all abutments and the occlusion type ( $p>0.05)$.

\subsubsection{Comparison of bleeding change and opposing arc types}

Chi-square test was performed to compare gingival bleeding changes in all regions of the first, second and third abutment teeth and the opposite arch type variable. According to the patient population in the study, the gingival bleeding change in all abutments does not depend on the type of arc ( $p>0.05)$.

\subsubsection{Comparison of bleeding changes and vitality types}

Chi-square test was applied to compare the gingival bleeding changes in all areas of the first, second and third abutment teeth and the vitality variable of the teeth. There is no statistically significant relationship between gingival bleeding change and vitality on all surfaces of all three abutments ( $p$ > $0.05)$.

\subsubsection{Comparison of bleeding change and attached gingiva amount changes}

Chi-square test was applied to examine the relationship between gingival bleeding changes in all areas of the first, second and third abutment teeth and the amount of attached gingiva. According to the 
sample, there is no significant difference between the gingival bleeding change in all abutments and the amount of attached gingiva ( $p>0.05)$.

\subsubsection{Comparison of bleeding change by root length variable}

The Kruskal Wallis test was applied to evaluate the relationship between gingival bleeding changes in all regions of the first, second and third abutment teeth and root length. There is no statistically significant relationship between gingival bleeding change on all surfaces of all three abutments and root length $(\mathrm{p}>0.05)$.

\subsubsection{Comparison of bleeding change by restoration lenght variable}

The Kruskal Wallis test was performed to evaluate the relationship between gingival bleeding changes in all areas of the first, second and third abutment teeth and the length of the restoration. There is no statistically significant relationship between the restoration length and gingival bleeding change in all abutment areas $(\mathrm{p}>0.05)$

\subsection{Change Findings in Plaque Amount}

\subsubsection{Comparison of plaque amount change with age}

Spearman correlation test was used for the relationship between the changes in the amount of plaque in all areas of the first, second and third abutment teeth and the age variable. There is no statistically significant relationship between the age variable and the change in the amount of plaque in any of the abutment teeth ( $p>0.05)$.

\subsubsection{Comparison of plaque amount change by gender groups}

Chi-square test was used for the relationship between the changes in the amount of plaque of the first, second and third abutment teeth and the gender variable. The change in the amount of plaque in all abutments according to the patient population in the study does not depend on the gender variable ( $p>$ $0.05)$.

\subsubsection{The relationship between plaque amount change and the distance between abutments}

Spearman correlation test was applied to evaluate the relationship between the changes in the amount of plaque in all regions of the first, second and third abutment teeth and the distance between the abutments. There is a statistically moderate relationship between the increase in the distance between the first and the second abutment and the decrease in the amount of plaque in the $\mathrm{P}$ region of the first abutment $(r=0.43 ; p=0.03)$. There is a statistically moderate correlation between the increase in the distance between the second and third abutment and the decrease in the amount of plaque in the $\mathrm{P}$ region of the second abutment $(r=0.58 ; p=0.003)$. There is also a statistically moderate relationship between the increase in the distance between the second and third abutment and the decrease in the amount of plaque in the $\mathrm{P}$ region of the third abutment $(\mathrm{r}=0.41 ; \mathrm{p}=0.045)$ (Table- 8 ).

Table-8. The relationship between plaque amount change and the distance between abutments

\begin{tabular}{|l|l|}
\hline & \multicolumn{1}{|c|}{ Change in Plaque Amount } \\
\cline { 2 - 2 } & Surface P of 1st abutment \\
\hline Distance between 1st and 2nd & $\mathrm{r}=0.43$ \\
abutments & $\mathrm{p}=0.03$ \\
\hline & Surface P of 2nd abutment \\
\hline Distance between 2nd and 3rd & $\mathrm{r}=0.58$ \\
abutments & $\mathrm{p}=0.03$ \\
\hline
\end{tabular}




\subsubsection{Comparison of plaque amount change and bridge angle}

Spearman correlation test was applied to compare the variations in the amount of plaque in all areas of the first, second and third abutment teeth and the bridge angle variable. There is no statistically significant relationship between the bridge angle variable and the change in the amount of plaque in any of the abutment teeth ( $>0.05)$.

\subsubsection{Comparison of plaque amount change by occlusion types}

Chi-square test was used for the relationship between plaque amount changes and occlusion type of first, second and third abutment teeth. According to the patient population in the study, the change in the amount of plaque in all abutments is not dependent on the occlusion type variable ( $p>0.05)$.

\subsubsection{Comparison of the change in plaque amount according to the types of opposing arcs}

Chi-square test was applied for the relationship between the changes in plaque amount of the first, second and third abutment teeth and the opposite arch type. According to the sample, there is no dependence of the change in the amount of plaque in all abutment regions on the opposite arch type variable according to the patient population ( $p>0.05$ ).

\subsubsection{Comparison of the change in plaque amount according to vitality types}

Chi-square test was applied for the relationship between the changes in plaque amount of the first, second and third abutment teeth and vitality. According to the patient population in the study, the change in the amount of plaque in all abutments is not dependent on the vitality variable $(p>0.05)$.

\subsubsection{Comparison of the change of plaque amount with the change of attached gingiva}

Chi-square test was used to compare the changes in the amount of plaque in all areas of the first, second and third abutment teeth and the variable of the amount of attached gingiva of the teeth. There is no statistically significant relationship between the change in the amount of plaque on all surfaces of all three abutments and the amount of attached gingiva ( $p>0.05)$.

\subsubsection{Comparison of change in plaque amount with root and restoration length}

Spearman correlation test was used for the relationship between the changes in the amount of plaque in all areas of the first, second and third abutment teeth and the variables of root length and restoration length. There is no statistically significant relationship between the variables of root length and restoration length of the first abutment tooth and the change of plaque amount of the abutment tooth ( $p>0.05$ ). While there is a statistically significant moderate and positive relationship between the variables of root length and plaque amount in the DB of the second abutment $(r=0.45 ; p=0.028)$; It can be said that there is a statistically significant, moderate and positive correlation between the variables of root length and plaque amount in the same fulcrum and $\mathrm{P}$ region $(\mathrm{r}=0.58 ; \mathrm{p}=0.003)$ (Table-9). There is a significant and moderately negative relationship between the length of the restoration in the $\mathrm{P}$ region of the second abutment tooth and the amount of plaque $(r=-0.44 ; p=0.03)$. There is no statistically significant relationship between the variables of root length and restoration length of the third abutment tooth and the change of plaque amount of the abutment tooth ( $p>0.05)$.

Table-9. The relationship between the change in the amount of the 2nd abutment plaque and root length

\begin{tabular}{|l|l|l|}
\hline \multirow{2}{*}{} & \multicolumn{2}{|c|}{ Root length change } \\
\cline { 2 - 3 } & \multicolumn{2}{|c|}{ 2nd abutment } \\
\cline { 2 - 3 } & \multicolumn{2}{|c|}{ DB } \\
\hline Change in Plaque & $\mathrm{r}=0.45$ & $\mathrm{r}=0.58$ \\
Amount & $\mathrm{p}=0.028$ & $\mathrm{p}=0.003$ \\
\hline \multicolumn{2}{|c|}{ Spearman Correlation Test } \\
\hline
\end{tabular}




\subsection{Findings of Change in Bone Amount}

3.5.1. Comparison of bone amount change with age

Spearman correlation test was used for the relationship between bone amount changes in the M and D regions of the first, second and third abutment teeth and the age variable. There is no statistically significant relationship between the age variable and the change in bone amount in all regions of the first and second abutment teeth ( $p>0.05$ ). However, there is a statistically moderate relationship with the age variable in terms of the increase in the amount of bone in the $\mathrm{D}$ region of the third abutment tooth $(\mathrm{r}=0.45 ; \mathrm{p}=0.03)($ Table-10).

Table-10. The relationship between bone amount change and age

\begin{tabular}{|l|l|l|l|l|}
\hline \multicolumn{2}{|c|}{} & \multicolumn{1}{c|}{$\mathrm{r}$} & \multicolumn{1}{c|}{$p$} \\
\hline \multirow{3}{*}{ Bone Amount Change } & \multirow{2}{*}{ 1st abutment surface } & $\mathbf{M}$ & 0,06 & 0,78 \\
\cline { 2 - 5 } & \multirow{2}{*}{ 2nd abutment surface } & $\mathbf{D}$ & 0,26 & 0,22 \\
\cline { 2 - 5 } & \multirow{2}{*}{ 3th abutment surface } & $\mathbf{M}$ & 0,13 & 0,55 \\
\cline { 3 - 5 } & & $\mathbf{M}$ & 0,02 & 0,91 \\
\cline { 3 - 5 } & $\mathbf{D}$ & 0,45 & $0,03^{*}$ \\
\hline
\end{tabular}

Spearman Correlation Test

\subsubsection{Comparison of bone amount changes according to gender groups}

The Chi-Square test was used for the relationship between bone amount changes in all parts of the first, second and third abutment teeth and the gender variable. There is no statistically significant relationship between the change in bone amount on all surfaces of all three abutments and gender $(\mathrm{p}$ > $0.05)$.

\subsubsection{Comparison of bone amount change and distance between abutments}

The Chi-Square test was used for the relationship between bone amount changes in all parts of the first, second and third abutment teeth and the distance between abutments. There is no statistically significant relationship between the change in bone amount of the 1st and 3rd abutment teeth ( $p>0.05)$. There is a positive and moderate statistical relationship between the bone increase in the $\mathrm{D}$ region of the second abutment and the distance between the first and second abutment teeth $(r=0.55 ; p=0.005)$ (Table-11).

Table-11. The relationship between bone amount change and bridge angle and distance between abutments

\begin{tabular}{|l|l|l|}
\hline & $\begin{array}{r}\text { Distance between 1st and 2nd } \\
\text { abutment }\end{array}$ & \multicolumn{1}{|c|}{ Bridge Angle } \\
\cline { 2 - 3 } & D surface of the 2nd abutment & Surface M of first abutment \\
\hline $\begin{array}{l}\text { Change in Bone } \\
\text { Amount }\end{array}$ & $\mathrm{r}=0.55$ & $\mathrm{r}=0.60$ \\
$\mathrm{p}=0.005$ & $\mathrm{p}=0.002$ \\
\hline
\end{tabular}

Chi-Square test

Spearman correlation test

\subsubsection{Comparison of bone amount change and bridge angle}

Spearman correlation test was applied for the relationship between bone amount changes in all parts of the first, second and third abutment teeth and the bridge angle variable. There is a high level of statistical relationship between the change in bone change amount in the $\mathrm{M}$ region of the first fulcrum and the bridge angle $(r=0.60 ; p=0.002)$. There is no statistically significant relationship between the 
change in the amount of bone change and the bridge angle in all regions of the second and third abutments $(\mathrm{p}>0.05)($ Table-11).

\subsubsection{The relationship between bone amount change and occlusion type}

Chi-square test was used for the relationship between bone amount changes in all regions of the first, second and third abutment teeth and the occlusion type variable. There is no statistically significant relationship between the change in bone amount on all surfaces of all three abutments and the type of occlusion ( $\mathrm{p}>0.05)$.

\subsubsection{Comparison of bone amount change according to opposing arc types}

The Chi-Square test was used for the relationship between bone amount changes in all regions of the first, second and third abutment teeth and the opposite arch type variable. There is no statistically significant relationship between the change in bone amount on all surfaces of all three abutments and the type of opposing arch ( $>>0.05)$.

\subsubsection{Comparison of bone amount change according to vitality types}

Chi-square test was used for the relationship between bone amount changes in all parts of the first, second and third abutment teeth and the vitality variable of the teeth. There is no statistically significant relationship between the change in bone amount on all surfaces of all three abutments and the vitality variable of teeth $(\mathrm{p}>0.05)$.

3.5.8. Comparison of the change in bone amount according to the change in the amount of attached gingiva

Chi-square test was used for the relationship between the changes in the amount of bone in all parts of the first, second and third abutment teeth and the variable of the amount of attached gingiva of the teeth. There is no statistically significant relationship between the change in the amount of bone on all surfaces of all three abutments and the variable of the amount of attached gingiva to the teeth ( $p>0.05)$.

\subsubsection{Comparison of bone amount change with root and restoration length}

Spearman correlation test was used for the relationship between bone amount changes in all parts of the first, second and third abutment teeth and the root length variable of the teeth and the restoration length variable. There is no statistically significant relationship between the change in the amount of bone change in all areas of all abutments and the root length and restoration length of the teeth ( $\mathrm{p}>0.05)$.

\subsection{Findings of Ceramic Fracture}

\subsubsection{Comparison of ceramic fracture by age variable}

The Mann-Whitney U test was used to compare the age variable of the presence of ceramic fractures in the restorations of the first, second and third abutment teeth. According to the sample, the age variable is independent of the ceramic fracture groups (yes-no) ( $p>0.05)$.

\subsubsection{Comparison of Ceramic Fracture by gender groups}

The Chi-Square test was used for the relationship between the gender variable of the presence of ceramic fractures in the restorations of the first, second and third abutment teeth. There is no statistically significant relationship between the presence of ceramic fractures in the restorations of all three abutments and gender $(\mathrm{p}>0.05)$.

3.6.3. Comparison of ceramic fracture according to the distance between abutments and bridge angle The Mann-Whitney U test was used for the comparisons between the presence of ceramic fractures in the restorations of the first, second and third abutment teeth, and between the bridging angle variable. According to the sample, the distance between abutments and the bridging angle variable are independent of the ceramic fracture groups (yes-no) $(\mathrm{p}>0.05)$.

\subsubsection{Comparison of ceramic fracture according to occlusion type groups}

The Chi-Square test was applied for the relationship between the occlusion type variable of the presence of ceramic fractures in the restorations of the first, second and third abutment teeth. There is no statistically significant relationship between the occlusion type of the presence of ceramic fractures in the restorations of all three abutment teeth $(\mathrm{p}>0.05)$. 


\subsubsection{Comparison of ceramic fracture by opposing arc type groups}

Chi-square test was applied for the relationship between the opposing arch type variable of the presence of ceramic fractures in the restorations of the first, second and third abutment teeth. There is no statistically significant relationship between the presence of ceramic fractures in the restorations of all three abutment teeth between the opposite arch type ( $p>0.05)$.

\subsubsection{Comparison of ceramic fractures according to vitality groups}

Chi-square test was applied for the relationship between the vitality variable of the teeth of the presence of ceramic fractures in the restorations of the first, second and third abutment teeth. There is no statistically significant relationship between the vitality variable of the teeth of the presence of ceramic fractures in the restorations of all three abutment teeth ( $p>0.05)$.

\subsubsection{Comparison of ceramic fracture according to the change in the amount of attached gingiva}

The Chi-Square test was applied for the relationship between the presence of ceramic fractures in the restorations of the first, second and third abutment teeth and the variable of the amount of attached gums on the teeth. There is no statistically significant relationship between the presence of ceramic fractures in the restorations of all three abutment teeth and the variable of the amount of adherent gingiva to the teeth $(\mathrm{p}>0.05)$.

\subsubsection{Comparison of ceramic fracture according to root and restoration length}

The Mann-Whitney U test was used to compare the presence of ceramic fractures in the restorations of the first, second and third abutment teeth between the variables of root length and restoration length of the teeth. According to the sample, root length and restoration length variables of the teeth are independent from the ceramic fracture groups (yes-no) ( $p>0.05$ ).

\subsection{Findings of Complication (Biological, Mechanical, Aesthetic)}

\subsubsection{Comparison of the type of complication by age variable}

The Kruskal Wallis test was used to compare the presence of complications of the first, second and third abutment teeth with the age variable. According to the sample, the age variable is independent of the complication groups ( $p>0.05)$.

\subsubsection{Comparison of the types of complications by gender groups}

Chi-square test was used for the relationship between the gender variable of the presence of complications of the first, second and third abutment teeth. There is no statistically significant relationship between the presence of complications in all three pillars and gender ( $p>0.05)$.

\subsubsection{Comparison of the type of complication with respect to the distance between abutments and bridge angle \\ The Kruskal Wallis test was applied to compare the presence of complications of the first, second and third abutment teeth with the variables of distance between abutments, bridge angle, root length of abutment teeth and restoration length. According to the sample, these variables are independent from the complication groups ( $p>0.05)$.}

\subsubsection{Comparison of complication types by occlusion types}

Chi-square test was applied for the relationship between occlusion type, opposing arch type, vitality of abutment teeth and the amount of attached gingiva in the presence of complications of first, second and third abutment teeth. There is no statistically significant relationship between the presence of complications in all three bases and these variables ( $p>0.05)$.

No bridge fracture was observed in any of the restorations included in the study.

\section{Discussion}

In our study, in which the fate of the biological, mechanical and aesthetic results of prosthetic treatment with periodic controls in patients who have been rehabilitated with a fixed bridge prosthesis with a middle-strength three member metal ( $\mathrm{Ni}-\mathrm{Cr}$ alloy) substructure, the fate of the biological, mechanical and aesthetic results of the prosthetic treatment was evaluated. This patient group was not included in the study because the abnormalities affect the immune response in the peridontal tissues (Kinane and Marshall 2001, Kim and Amar 2006). With the same thought, smokers were also excluded from the 
study, considering that smoking was also considered as risk factors in periodontal diseases, negatively affected the response to treatment, and negative effects on tissues (Kinane and Chestnutt 2000, Zee 2009).

Fixed prosthetic rehabilitation alternatives in partial edentulism vary according to connection morphologies. The prosthesis type that combines the base tooth with the body part is a rigid connection with solder or casting connection, and the prosthesis type that provides a sensitive or tension-cutting connection with the tooth is non-rigid attachment prostheses (Banerjee et al 2011, Fayyad and ALRafee 1996). Non-rigid fixed prosthetic restorations can be preferred today in rigid-anchored fixed bridge prostheses, regardless of the idea that the middle abutment faces mechanical problems in the long term and to reduce tooth preparations.

When we look at the literature, Fayyad and Rafee reported in their study that caries and periodontal diseases are the most important causes of failure in fixed prostheses (Fayyad and AL-Rafee 1996). It is also stated in many studies that periodontal tissue diseases increase with age (Efeoğlu et al 2000, Uzel 2012, Shillingburg et al 2010). It has been shown that the prevalence of periodontal diseases in young people (15-25 years) is $26.9 \%$, and this rate is $70.27 \%$ in middle-aged individuals (45-60 years) (Shillingburg et al 2010). In other studies examining the relationship between periodontal disease and the ages of individuals, periodontal disease was detected in $8 \%$ of individuals between the ages of 9-12, $1.4 \%$ of individuals aged $13-17,50 \%$ of individuals aged 18-64, and $88 \%$ of individuals aged 65 and over (Toksavul and Yilmaz 2002, Sailer et al 2007). However, contrary to the literature view, considering the relationship between the gingival index parameter and age in our study, the increase in the gingival index in the first and second abutment teeth does not show a proportional increase in age, and there is an inverse proportion between the increase in the gingival index on the B surface of the third abutment and age. In the measurement of clinical attachment loss, there is an inverse relation between the $\mathrm{D}$ surfaces of the third abutment teeth and the increase in age. However, the increase in the amount of gingival pockets of the second and third abutment teeth with increasing age is in parallel with the literature. It was concluded that there was no relationship between age and bleeding during probing. Based on these results, we think that the age parameter alone is not sufficient to affect the periodontal tissue health in fixed prostheses with a medium base.

In studies evaluating the relationship of periodontal diseases with gender, the incidence of gingival recession was found to be different according to gender. Khosya and Devaraj found that $58.6 \%$ of the 244 individuals with periodontal diseases they included in their study were male and $41.4 \%$ were female (Sailer et al 2007). Similarly, Mythri et al. found that periodontal diseases are more common in men $(60.5 \%)$ (Shillingburg et al 2010). In addition, Kozlowska et al stated that periodontal diseases are seen more frequently in women with a rate of $74 \%$ (Baran and Nalçac1 2007). In our study, in the relationship between gingival index, which is one of the periodontal disease markers, and gender, the mean gingival index score on the $\mathrm{MB}, \mathrm{B}, \mathrm{DB}$ and $\mathrm{P}$ surfaces of the abutment teeth was higher in men than women in the first control, while the mean gingival index on the MB surface in men, $\mathrm{B}, \mathrm{DB}$ and $\mathrm{P}$ on the surface, it was found higher in women. Although there is no relationship between other periodontal parameters and gender, its relationship with the gingival index shows a decrease in males and an increase in females, which provides a different finding to the literature.

In the finite element analysis and biomechanical evaluations of rigid-connected bridge prostheses made by Modi et al, it has been stated that the stress accumulation in the molar teeth is less than the pier abutment and canine teeth (Leempoel et al 1989). Awadalla et al, Pesun et al, and Oruç et al also support this view by attributing the greater periodontal membrane area of molar teeth compared to single root teeth (Yang and Chung 1996, Silness et al 1982, Nigiz et al 2006). In our study, the increase in the distance between the 2nd and 3rd abutment caused a decrease in the amount of pockets and plaque in more areas compared to the increase of the distance between the 1st and 2nd abutment teeth. Based on these findings, it can be said that the distance between the middle fulcrum tooth and the distal tooth is more positive than the distance between the mesial tooth and the tooth in terms of periodontal health. These findings are in line with the literature stating that the stress accumulation in the 3rd abutment is less than the pier abutment and canine teeth in the finite element analysis studies on bridges with pier abutment.

In the fixed prosthetic restoration treatment, in order to protect the health of the periodontal tissue and not to damage the restoration components, the opposite arch type and occlusion type of the restoration are very important factors. In the study conducted by $\mathrm{Yi}$ et al, 43 fixed partial bridge prostheses have bilateral balanced occlusion, opposing natural tooth, natural tooth + partial fixed restoration in patients with opposing arch total prosthesis, and canine preservative and group function occlusion in patients

139 | P a g e

www.iiste.org 
with partial removable prostheses. It was reported that satisfaction was achieved and no complications were experienced depending on these parameters after 10 years of follow-up (Hirshberg, 1972). In our study, there is a relationship between the variables that we evaluated with group function and canine preservative occlusions applied in patients with counter-arch natural tooth (10 patients), fixed restoration (11 patients), natural tooth + partial fixed restoration (1 patient) and partial removable prosthesis ( 2 patients). We can say that adherence to prosthetic rules can help in the management of mechanical and biological complications in the long term, since they cannot be detected.

Vitality loss of teeth is a common complication in fixed denture restorations. Reichen-Graden et al reported in their study that $3.7 \%$ of the fixed bridge restorations applied to 58 patients had loss of abutment tooth vitality after 4 to 8 years of follow-up (Abduo, 2016). The results in our study show that the gingival index changes of all teeth are not related to the vitality of the teeth or are very weak. In addition, considering the relationship between vitality of abutments and gingival pocket amount, it can be said that there may be a relationship between periodontal tissue health parameters and pulp vitality of teeth due to the higher amount of pockets on DP surfaces of vital second abutment teeth.

Various opinions have been made about the necessity of attached gingiva deficiency in terms of periodontal health. In the study of Mehta and Peng, it was stated that if oral hygiene is provided, excessive amount of attached gingiva will not have an effect on periodontal health. However, it was concluded that the thin attached gingiva around the teeth with restoration and orthodontic treatment is more susceptible to recession and may be aesthetically needed (Çağlar, 2015). In line with the data of our study, we can state that the amount of attached gingiva does not show parallelism on the change of gingival index, one of the periodontal health parameters, and we can say that similar findings were obtained with the literature.

Considering the effect of root morphologies of abutment teeth in fixed bridge prosthesis on periodontal health in the literature, they stated in the meta-analysis study conducted by Ercoli et al that stating that abutment tooth anatomies and root morphologies may be factors that may cause plaque retention and increase the possibility of gingivitis and periodontitis (Almeida, 2013). In our study, we think that the positive relationship between the increase in the plaque index and the root length increase of the second abutment teeth, in addition to the knowledge of the relationship between root morphology and plaque retention in the literature, may suggest that the increase in root length may increase the accumulation of plaque.

One of the reasons for the lack of oral hygiene is restoration morphology. There are many studies reporting that plaque accumulation is higher in restorations with subgingival margins compared to those with supragingival margins (Seelbach et al 2013, Luthardt et al 2000). In our study, it partially complies with the literature, suggesting that there may be a parallel relationship between the increase in the length of the subgingival prosthetic restoration and the decrease in the plaque index on the $\mathrm{P}$ surface of the second abutment tooth, and the increase in the restoration surface area and the increase in the effectiveness of the toothbrush.

Looking at the mechanical complications of metal-supported ceramic prostheses, ceramic fractures can be seen frequently in the long term (Ucar et al 2009). In our study, a statistically significant relationship was not found between any of the variables of age, gender, distance between abutments, bridge angle, occlusion type, opposing arch type, vitality, amount of attached gum and root length. We think that this situation may occur due to idiopathic reasons.

\section{Conclusions}

In our study, in the loss of clinical attachments, the occurrence of periodontal diseases or complications related to the restoration in patients who underwent rigid-linked fixed prosthetic restoration, findings that are compatible with the literature and provide new information to the literature were determined with the changes recorded in the controls. For this reason, when we consider the fact that non-rigid bonded restorations require precise laboratory work, we think that rigid-linked fixed prosthetic restorations will be more advantageous in laboratory practice, based on our study, which we think that clinical and radiological complications do not have a definite relationship with the type of restoration.

\section{Acknowledgement}

Authors confirm that the articles are original.

There's no conflicts of interests or any plagiarism issues.

The article is not being considered elsewhere.

$\mathbf{1 4 0} \mid \mathrm{P}$ a g e

www.iiste.org 
The authors are willing to transfer the first publishing right to the publisher if the article is accepted after review.

\section{References}

Abduo, J. (2016). Axial contour alteration following restorative treatment: Systematic review. Periodon Prosthodon; 2:1.

Almeida e Silva, J.S., Erdelt, K., Edelhoff, D., Araujo, E., Stimmelmayr, M., Vieira, L.C.C, et al. (2013). Marginal and internal fit of four-unit zirconia fixed dental prostheses based on digital and conventional impression techniques. Clinical Oral Investigations; 18: 515-523.

Banerjee, S., Khongshei, A., Gupta, T. and Baneerjee, A. (2011). Non-rigid connector: the wand to ally the stresses on abutment. Contemp Clin Dent; 2:351-54.

Baran, İ. and Nalçacı, R. (2007). Diş hekimliğinde kullanılan materyaller ve alerjik reaksiyonlar. Atatürk Üniv. Diş Hek. Fak. Derg.; 2 :26-32.

Çağlar, İ., Yeşil Duymuş, Z. and Ateş, S.M. (2015). Diş hekimliğinde kullanılan ölçü sistemlerinde güncel yaklaşımlar:Dijital ölçü. Atatürk Üniv. Diş Hek. Fak. Derg:10; 135-140.

Efeoğlu, A., Demirhan Erdemir, A. and Öncel, Ö. (2000). Başlangıçtan Günümüze Diş Hekimliği. İstanbul: Nobel Tip Kitapevleri. 90.

Fayyad, M.A. and AL-Rafee, M.A. (1996). Failure of dental bridges. II. Prevalence of failure and its relation to place of construction. Journal of Oral Rehabilitiation, 23,438-440.

Hirshberg, S.M. (1972). The relationship of oral hygiene to embrasure and pontic design-A preliminary study. J Prosthet.Dent; 27:1.

Kim, J. and Amar, S. (2006). Periodontal disease and systemic conditions: a bidirectional relationship. Odontology, September; 94(1): 10-21.

Kinane, D.F. and Chestnutt, I.G. (2000). Smoking and periodontal disease. Critical Reviews in Oral Biology \& Medicine, 11(3):356-365.

Kinane, D.F. and Marshall, G.J. (2001). Periodontal manifestations of systemic disease. Australian Dental Journal, 46:(1):2-12.

Leempoel, J.B., Vanrossum, G.M.J.M., Dehaan, A.J. and Reintjes, G.M. (1989). Bridges in general dental practices: a descriptive study of the types of bridges and patients. J Oral Rehabilitation; 16: 381-386.

Luthardt, R.G., Stößel, M., Hinz, M. and Vollandt, R. (2000). Clinical performance and periodontal outcome of temporary crowns and fixed partial dentures: A randomized clinical trial. The journal of prosthetic dent; 83:1.

Nigiz, R., Dağ, A., Zengingül, A.İ. and Akkuş, M. (2006). Sabit protezlerde köprü gövdesinin ağız mukozasında oluşturduğu histopatolojik ve klinik değişiklikler. Dicle Tıp Derg; 33,2: 59-62.

Roberts, M. (2013). Strategies for integrating new restorative materials with digital technology and sound restorative principles. Compend Contin Educ Dent Jan;34(1):52-7, 59. 
Sailer, I., Pjetursson, B.E., Zwahlen, M. and Hammerle, C.H.F. (2007). A systematic review of the survival and complication rates of all-ceramic and metal-ceramic reconstructions after an observation period of at least 3 years. Part II: fixed dental prostheses. Clin. Oral Impl. Res;18 :86-96.

Seelbach, P., Brückel, C. and Wöstmann, B. (2013). Accuracy of digital and conventional impression techniques and workflow. Clinical Oral Investigations;17:1759-64.

Shillingburg, H.T., Hobo, S., Whitsett, L.D. and Brackett, S.E. (2010). Sabit protezin temelleri, çeviri editörleri: Ünsal K, Üşümez A, III. Baskı, Quintessence yayıncılık.

Silness, J., Gustavsen, F. and Mangersnes, K. (1982). The relationship between pontic hygiene and mucosal inflammation in fixed bridge recipients. J Periodontal Res Jul;17(4):434-9.

Toksavul, S. and Yılmaz, G. (2002). Bölümlü Protezler. İzmir: Ege Üni. Diş Hek. Fak. Yayınları. 7.

Ucar, Y., Akova, T., Akyil, M.S. and Brantley, W.A. (2009). Internal fit evaluation of crowns prepared using a new dental crown fabrication technique: Laser-sintered $\mathrm{Co}-\mathrm{Cr}$ crowns. J Prosthet Dent;102:253-259.

Uzel, İ. (2012). Diş Hekim Biliminde 'İlk’ler. İstanbul: İstanbul Aydın Üni. Diş Hek. Fak. Yayınları. 123, 72, 173 .

von Stein-Lausnitz, M., Nickenig, H.J., Wolfart, S., Neumann, K., von Stein-Lausnitz, A., Spies, BC. and Beuer, F. (2019). Survival rates and complication behaviour of tooth implantsupported, fixed dental prostheses: A systematic review and meta-analysis. $\mathrm{J}$ Dent. Sep;88:103167.

Walton, T.R. (2015). An Up-to-15-Year Comparison of the Survival and Complication Burden of Three-Unit Tooth-Supported Fixed Dental Prostheses and Implant-Supported Single Crowns. Int J Oral Maxillofac Implants Jul-Aug;30(4):851-61.

Yang, H.S. and Chung, H.J. (1996) Stress analysis of cantilevered fixed partial denture with normal and reduced bone support. J Prosthet Dent; 76:424-30.

Zee, K.Y. (2009). Smoking and periodontal disease. Australian Dental Journal, 54:(1 Suppl): 4450. 